Original Article

\title{
Analysis of injuries in taekwondo athletes
}

\author{
MinJoon Ji, $\mathrm{PhD}^{1)}$ \\ 1) Department of Sports Science, College of Natural Science, Kyungnam University: 7 Kyungnamdaehak-ro, \\ Masanhappo-gu, Changwon-si, Gyeongsangnam-do 631-701, Republic of Korea
}

\begin{abstract}
Purpose] The present study aims to provide fundamental information on injuries in taekwondo by investigating the categories of injuries that occur in taekwondo and determining the locations of these injuries. [Subjects and Methods] The data of 512 taekwondo athletes were collected. The sampling method was convenience sampling along with non-probability sampling extraction methods. Questionnaire forms were used to obtain the data. [Results] The foot, knee, ankle, thigh, and head were most frequently injured while practicing taekwondo, and contusions, strains, and sprains were the main injuries diagnosed. [Conclusion] It is desirable to decrease the possibility of injuries to the lower extremities for extending participation in taekwondo. Other than the lower extremities, injuries of other specific body parts including the head or neck could be important factors limiting the duration of participation. Therefore, it is necessary to cope with these problems before practicing taekwondo.

Key words: Taekwondo, Injury location, Injury type
\end{abstract}

(This article was submitted Sep. 9, 2015, and was accepted Oct. 16, 2015)

\section{INTRODUCTION}

Taekwondo is a traditional Korean martial art currently practiced in over 206 countries around the world ${ }^{1)}$ and has highprofile educational and physical values ${ }^{2}$. Due to its various kicking and efficient attacking techniques ${ }^{3)}$, taekwondo has become a globalized sport and finally obtained full status in the official Summer Olympic competition program since the 2000 Sydney Olympics ${ }^{4}$. As a martial art sport, taekwondo is characterized by its emphasis on dynamic techniques for taking mobile stances, and agility, speed, flexibility, and endurance are required to perform the whole process efficiently ${ }^{5)}$. With respect to fitness, taekwondo can provide participants with health benefits and a sound mind.

Despite its perceived physical usefulness for all ages, practicing taekwondo may cause various types of injuries because it involves intense full-contact sparring. Active participation in sport is generally recognized as positive, but participation in any type of sports always has the possibility of injury ${ }^{5,6)}$. Indeed, it is reported that several taekwondo-related activities cause accidental injuries owing to its attribute of contact $^{7}$. Because of the essential characteristics of martial arts, any collision or injury in taekwondo is considered natural. Especially during full-contact sparring in taekwondo, owing to the physical demands and force imposed on the athlete, the risks of injury must be addressed ${ }^{8}$.

According to previous research, some injury risks from practicing martial arts are unnecessary and preventable ${ }^{9}$, and are seen as critical health problems in Western societies ${ }^{10}$. Moreover, some kinds of injuries resulting from competitions can have a negative influence on participants in taekwondo who want to prolong the duration of their participation in the sport. Thus, injuries in taekwondo could be considered important issues and should be treated as key factors to help improve conditions for exercising or competing in taekwondo.

Therefore, examining the types of injuries resulting from performing taekwondo and their locations in detail are useful for deciding how to cope with injuries and prevent participants from unwarranted injuries. Also, even though there are some well-documented epidemiology injury profiles on taekwondo around the world ${ }^{11)}$, because taekwondo takes a relatively long time to attain proficiency in various kicking and sparring techniques, few systematic studies have been conducted on the 
long-term perspective in Korea. Therefore, this study aimed to provide fundamental information on injuries in taekwondo by investigating the categories of injuries in taekwondo and determining their locations.

\section{SUBJECTS AND METHODS}

A total of 535 participants who performed taekwondo were included in the study. The survey was conducted from March 5, 2014 to September 24, 2014. Questionnaire forms were used to collect the data and were distributed to participants who regularly practiced taekwondo in Gyeongnam Province. The sampling method was convenience sampling using nonprobability sampling extraction methods. All participants provided consent for data collection. While collecting the data, the purpose of this study was explicitly explained, and participants were asked whether they would like to take part in the research. The fact that any response to the questionnaire items would be confidential in all circumstances was also explained to the participants. Participants who had visited a medical institution more than thrice and were diagnosed with injuries resulting from taekwondo activities were included in the study. Even though prospective participants experienced medically diagnosed injuries before, participants who visited medical care centers fewer than two times or did not receive a definite diagnosis were excluded.

The form included items on age, gender, length of practice, injury diagnosis, and injury locations. On the questionnaire, the length of practice was categorized as follows: 1) less than 1 year since the beginning, 2) 1 through 3 years, and 3) more than 3 years. For the classification of injury diagnosis and locations, the criteria that Kazemi et al. used in 2009 were adopted $^{12)}$. According to these criteria, injury diagnoses were categorized as contusions, sprains, strains, fractures, joint dysfunction, and concussion of the brain, and injury locations were divided into head, foot, thigh, knee, ankle, trunk, wrist, forearm, and other parts of the body.

After completing the survey, all of the questionnaires were gathered and examined closely to exclude incorrectly completed forms. After 23 untrustworthy forms were excluded, 512 questionnaires were confirmed as the raw data sources. SPSS version 15.0 was used for data analysis. Frequency analysis was used to review the population statistics of the participants. Additionally, by using the multiple response method, the current status and types of injuries that occurred while practicing taekwondo were examined. The characteristics of the subjects are presented in Table 1.

\section{RESULTS}

Of 512 subjects, there were 277 males and 235 females with injuries recorded using a binary multiple response method. Among the participants included, the top five most frequent locations of injury, in order of decreasing frequency, were the foot $(n=93)$, knee $(n=86)$, ankle $(n=80)$, thigh $(n=64)$, and head $(n=61)$. Other minor locations of injury, such as the leg $(n=48)$, toes $(n=31)$, and back $(n=25)$ were also reported. Taking a closer look at the injury diagnoses, the five major injuries were contusions $(n=319)$, strains $(n=89)$, sprains $(n=75)$, fractures $(n=51)$, and concussions $(n=50)$. In addition, a few cases of joint dysfunction $(n=47)$ and lacerations $(n=11)$ were also reported. The injury locations and diagnoses are presented in Tables 2 and 3.

\section{DISCUSSION}

This study aimed to provide guidance on how to cope with injuries resulting from taekwondo participation by investigating the current status and types of injuries. From the analysis on injury locations, it was found that the vast majority of taekwondo participants experienced podiatric-related injuries. Although the term taekwondo is described as the martial art that uses kicks and punches concurrently, and victory at competitions is acquired by getting higher points from the judges and by performing specific techniques including kicks and punches ${ }^{13)}$, foot-related skills were preferred during sparring and demonstrations. However, because kick techniques are more powerful and more effective for scoring points than punches during competitive performances. Most of the skills used in taekwondo are dependent on kick techniques to efficiently score points in competitions. In previous studies, it was reported that the vast majority of injuries in participating athletes in taekwondo were found on the lower extremities owing to the exchange of accurate and powerful turning kicks ${ }^{14,15)}$. Furthermore, while conducting kicking techniques during competitions, taekwondo athletes often exchange kicks concurrently, which can result in lower extremity injuries. For athletes who highly use kicking to gain high scores, the frequencies of lower-extremities injuries may be increased. Therefore, it is necessary to decrease the possibility of injury to the lower extremities to extend participation in taekwondo. Other research has also cited that head or neck injuries are also prevalent in taekwondo ${ }^{16)}$. Therefore, it is necessary to address this issue while practicing taekwondo.

The main diagnoses in the present study were contusions, strains, and sprains. Taekwondo training generally consists of three sections, which can be divided into poomsae (the form that combines postures of the basic techniques of attack and defense), sparring, and breaking. Participants involved in sparring or breaking seem most likely to experience these types of injuries. Sparring is performed through fierce and speedy contact with the partner, therefore, contusions and sprains are common. While breaking objects, owing to contact with the object to break, athletes were more likely to experience injuries such as contusions and strains. 
Table 1. Subject characteristics $(\mathrm{n}=512)$

\begin{tabular}{lcc}
\hline Category & Frequency & $\%$ \\
\hline Age (years) & & \\
$10-19$ & 351 & 69 \\
$20-29$ & 114 & 22 \\
$\geq 30$ & 47 & 9 \\
Gender & & \\
Male & 277 & 54 \\
Female & 235 & 46 \\
Length of practice (years) & & \\
$<1$ & 135 & 26 \\
$1-3$ & 308 & 60 \\
$>3$ & 69 & 14 \\
\hline
\end{tabular}

Table 3. Injury diagnosis

\begin{tabular}{lcr}
\hline Diagnosis & Frequency & $\%$ \\
\hline Contusion & 319 & 48.4 \\
Strain & 89 & 13.5 \\
Sprain & 75 & 11.4 \\
Fracture & 51 & 7.7 \\
Concussion & 50 & 7.6 \\
Joint dysfunction & 47 & 7.1 \\
Laceration & 11 & 1.7 \\
Dislocation & 8 & 1.2 \\
Epistaxis & 5 & 0.8 \\
Other & 4 & 0.6 \\
Total & 659 & 100.0 \\
\hline
\end{tabular}

Table 2. Injury location

\begin{tabular}{lcc}
\hline Location & Frequency & $\%$ \\
\hline Foot & 93 & 16 \\
Knee & 86 & 14.8 \\
Ankle & 80 & 13.8 \\
Thigh & 64 & 11.1 \\
Head & 61 & 10.5 \\
Leg & 48 & 8.3 \\
Toes & 31 & 5.3 \\
Back & 25 & 4.3 \\
Hand & 18 & 3.1 \\
Finger & 15 & 2.6 \\
Shoulder & 10 & 1.7 \\
Arm & 9 & 1.6 \\
Neck & 9 & 1.6 \\
Trunk & 8 & 1.4 \\
Hip & 7 & 1.2 \\
Elbow & 6 & 1 \\
Wrist & 6 & 1 \\
Forearm & 4 & 0.7 \\
Total & 580 & 100.0 \\
\hline
\end{tabular}

Previous research cites that regardless of experience levels in taekwondo, almost all participants experienced contusions and strains ${ }^{12}$. In general, these kinds of injuries are expected because martial arts such as taekwondo involve extremely intensive body contact. However, if ignored, these types of injuries could be threats to prolonged participation in taekwondo because the repetitive and sustained activities could worsen the injury. To improve and prevent this situation, establishment of injury surveillance systems focusing on taekwondo is required, and educational programs for taekwondo instructors or coaching staffs to protect athletes should be strengthened.

\section{ACKNOWLEDGEMENT}

This study was supported by a Kyungnam University Foundation Grant, 2013.

\section{REFERENCES}

1) WTF (World Taekwondo Federation): www.worldtaekwondofederation.net.

2) Kim DY, Seo BD, Choi PA: Influence of taekwondo as security martial arts training on anaerobic threshold, cardiorespiratory fitness, and blood lactate recovery. J Phys Ther Sci, 2014, 26: 471-474. [Medline] [CrossRef]

3) Byun S, An C, Kim M, et al.: The effects of an exercise program consisting of taekwondo basic movements on posture correction. J Phys Ther Sci, 2014, 26: 1585-1588. [Medline] [CrossRef]

4) Lystad RP, Pollard H, Graham PL: Epidemiology of injuries in competition taekwondo: a meta-analysis of observational studies. J Sci Med Sport, 2009, 12: 614-621. [Medline] [CrossRef]

5) Lystad RP, Graham PL, Poulos RG: Exposure-adjusted incidence rates and severity of competition injuries in Austra- 
lian amateur taekwondo athletes: a 2-year prospective study. Br J Sports Med, 2013, 47: 441-446. [Medline] [CrossRef]

6) Atay E: Prevalence of sport injuries among middle school children and suggestions for their prevention. J Phys Ther Sci, 2014, 26: 1455-1457. [Medline] [CrossRef]

7) Varkiani M, Alizadeh M, Pourkazemi L: Comparison of children and youth taekwondo injuries via sport medicine federation injury surveillance system in Iran, 2009-2010. Procedia Soc Behav Sci, 2013, 82: 542-545. [CrossRef]

8) Birrer RB, Halbrook SP: Martial arts injuries. The results of a five year national survey. Am J Sports Med, 1988, 16: 408-410. [Medline] [CrossRef]

9) Oler M, Tomson W, Pepe H, et al.: Morbidity and mortality in the martial arts: a warning. J Trauma, 1991, 31: $251-253$. [Medline] [CrossRef]

10) Finch C, Valuri G, Ozanne-Smith J: Sport and active recreation injuries in Australia: evidence from emergency department presentations. Br J Sports Med, 1998, 32: 220-225. [Medline] [CrossRef]

11) Altarriba-Bartes A, Drobnic F, Til L, et al.: Epidemiology of injuries in elite taekwondo athletes: two Olympic periods cross-sectional retrospective study. BMJ Open, 2014, 4: e004605. [Medline] [CrossRef]

12) Kazemi M, Chudolinski A, Turgeon M, et al.: Nine year longitudinal retrospective study of Taekwondo injuries. J Can Chiropr Assoc, 2009, 53: 272-281. [Medline]

13) www.kukkiwon.or.kr.

14) Pieter W, Bercades L, Heijmans J: Injuries in young and adult taekwondo athletes. Kines, 1998, 30: 22-30.

15) Cunningham C, Cunningham S: Injury surveillance at a national multi-sport event. Aust J Sci Med Sport, 1996, 28: 50-56. [Medline]

16) Pieter W, Zemper ED: Head and neck injuries in young taekwondo athletes. J Sports Med Phys Fitness, 1999, 39: 147-153. [Medline] 